\title{
Sentido de lugar y género en Condorito y Mafalda
}

Condorito de René Ríos Boettiger (Pepo) y Mafalda de Joaquín Lavado (Quino) son dos de las historietas más populares en todo el mundo. Doreen Massey propone el concepto de sentido de lugar para referirse a la serie de relaciones sociales, económicas y políticas que operan en los espacios y determinan los papeles genéricos que hombres y mujeres desempeñan en la sociedad. El presente artículo analiza cómo se utilizan las estrategias gráficas en Condorito y Mafalda para desestabilizar o afianzar los papeles genéricos y el sentido de lugar de hombres y mujeres, tanto en el espacio público como en el espacio privado en la sociedad latinoamericana.

Palabras clave: Sentido de lugar, género, Mafalda, Condorito, historietas

Condorito, by René Ríos Boettiger (Pepo), and Mafalda, by Joaquín Lavado (Quino), are two of the most widely recognized comics in the world. Doreen Massey uses the concept of sense of place to refer to the network of social, economic, and political relationships that operate in a particular space and define gender roles. This article analyzes how various graphic strategies are used in Mafalda and Condorito to emphasize or contest men's and women's gender roles and sense of place in private and public spaces within Latin American societies.

Keywords: Sense of place, gender, Mafalda, Condorito, comics

En el libro Space, Place and Gender (1994), Doreen Massey analiza cómo se definen los individuos en cuanto al género a partir de los espacios que ocupan y qué incidencia tienen las relaciones sociales, políticas y económicas en dichos espacios. La geógrafa británica establece diferencias fundamentales entre los conceptos de espacio y sentido de lugar. Para Massey, el espacio lo constituye todo lo que existe en la superficie incluyendo los accidentes geográficos y, sobre todo, el diseño de las ciudades, las instituciones gubernamentales y los conglomerados económicos o sociales (5). El sentido de lugar se refiere al entramado de relaciones sociales, económicas y de poder que se establecen en el espacio y que asignan papeles específicos a los individuos ya sean hombres o mujeres dentro de una sociedad (6). En este estudio, me propongo explorar las 
relaciones entre espacio y lugar, y cómo se crean o subvierten los diversos papeles genéricos en las historietas Condorito y Mafalda.

Condorito fue creado por el gran caricaturista chileno René Ríos Boettiger, también conocido como Pepo. La historieta surgió en I949 como una respuesta al intento de Walt Disney por crear un personaje que representara a individuos típicamente latinoamericanos en la película Saludos amigos. Juan Poblete ha señalado cómo Disney falla en su intento colonizador de representar a Chile por medio del avión llamado Pedrito, mientras que Pepo consigue el éxito rotundo al crear a Condorito, una figura antropomórfica basada en el pájaro mítico de Los Andes (35). La tira se publicó por primera vez en 1949 en la revista Okey en Santiago de Chile, para luego producirse en revistas numeradas trimestralmente desde 1970 hasta 1979. En los años ochenta, la tira se internacionalizó y popularizó en varios países de habla hispana. Hoy en día, Condorito es, junto con Mafalda, una de las tiras más populares en todo el mundo, ya que se publica en diecinueve países con un tiraje de 1369 millones de ejemplares al año.

La caracterización de Condorito combina a dos personajes muy distintivos de la cultura chilena: el "roto" y el "huaso". El primero es el chico que emigra del campo a la ciudad y deambula por las calles en busca de modos de sobrevivir. El huaso es el vaquero chileno que se distingue por su amor al trabajo. Al hablar de los orígenes de Condorito, Jorge Montealegre afirma: "Era la síntesis del cóndor, el roto y el huaso pobre". En el artículo publicado por Alejandra Loreto González Hermosilla acerca de los rasgos característicos de la identidad chilena presentes Condorito, la autora cita las siguientes declaraciones de Pepo con respecto el origen del personaje:

Pepo: Walt Disney había elegido para nuestro país una figura tierna, pero muy poco humana, era el avioncito Pedro, ... en honor a Don Pedro Aguirre Cerda.

Condorito: ¿Entonces tú pensaste en mí?

Pepo: ... Pensé en el huemul y el cóndor, pensé que entre las dos figuras tú estabas más cerca de lo que somos nosotros... Preferí el cóndor. Por eso te hice bajar a ti de la cordillera, te calcé ojotas, te puse sombrero de huaso, te hice hablar y vivir en el mundo de los humanos. Tú serías uno más de nosotros, Condorito. (56)

En esta entrevista figurada entre el personaje y su creador, el uso del pronombre nosotros se refiere al lado humano que Pepo quería infundirle al protagonista de sus historietas. Por otro lado, como bien lo señala González Hermosilla, en la creación de Condorito se distingue lo propio que identifica a los chilenos. Por ello, Pepo dibuja a Condorito como un cóndor, lo viste del traje típico del huaso y lo rodea de un grupo de fieles amigos muy representativos de la cultura chilena, tales como Don Chuma, Ungenio, 
Huevo, Fonola y Garganta de Lata, entre otros. La novia de Condorito es Yayita, una mujer hermosa que también recibe las atenciones de Pepe Cortisona, el rival de Condorito.

El espacio en el que se mueve Condorito es la ciudad ficticia de Pelotillehue, donde realiza varios trabajos con bastante éxito. Sin embargo, en algunas de las historietas, Condorito se caracteriza como el roto, ya que lleva una camisa agujereada, un pantalón con remiendos y un hatillo al hombro que comunica a los lectores el nomadismo típico de alguien que vive en la calle. Siguiendo el planteamiento de Massey, en la historieta titulada "Decente" (fig. I), Condorito es un individuo marginal cuyo sentido de lugar se define por la relación social que establece en ese momento con una chica desconocida en un parque de la ciudad. Para la geógrafa británica, el sentido de lugar debe ser pensando como: "as formed out of social interrelations at all scales, then one view of a place is as a particular articulation of those relations, a particular moment in those networks of social relations and understandings" (5) que varían de acuerdo con el tiempo y al espacio (I78). Es decir, Condorito cambia de espacio y al mismo tiempo transforma su sentido de lugar en la mayoría de las tiras porque establece nuevas relaciones sociales en los diversos oficios que ejerce (vagabundo, cura, dentista, soldado, médico, etc.). En la tira "Decente", Condorito no encuentra vivienda, razón por la cual debe dormir en una banca de un parque y convertirse en vagabundo. La historieta consta de seis cuadros en los que predomina una paleta de colores derivada del rojo que se mezcla con colores terciarios como el rosado fuerte y el ocre, el blanco, el negro y el gris, formando lo que califica Roberto Bergado como "una armonía de colores complementarios" (I33) que acentúa la precariedad de la situación de Condorito. La utilización de dichos colores y el uso de las sombras indican que ya se acerca la noche.

El parque donde tiene lugar la escena representada en "Decente" se constituye en un espacio que connota no solamente la condición social precaria de Condorito, sino también una situación interesante en términos de género. En la banca del parque se encuentra sentada una mujer pelirroja muy atractiva. El dibujo presenta una imagen hipersexualizada de la chica ya que ella es dibujada con grandes senos, cintura pequeña, amplia cadera y largas piernas. En esta historieta, la hipersexualización del personaje femenino apunta hacia la baja reputación que una mujer adquiere por andar por la calle de noche. Debido a ello, no es sorpresivo que Condorito le proponga: “¿Le parece que entre nosotros puede existir algo?" (Pepo 42.056). Después de aclarar que ese "algo" se refiere a un romance, la muchacha responde: "iY para que sepa, soy una mujer decente!" (Pepo 42.056). Condorito replica con un chiste: “Entonces qué hace en mi cama?" 
(Pepo 42.056). Aunque este apunte tiene un lado jocoso que surge por la incongruencia de su comentario según John Morrell, también revela un código cultural: una mujer respetable no debería estar en el espacio público cuando cae la noche, ya que ese no es su lugar. Es decir, tradicionalmente el espacio público lo deben habitar los hombres, aunque sean individuos marginales como Condorito. ${ }^{\mathrm{I}}$

En BodySpace: Destabilizing Geographies of Gender and Sexuality, Nancy Duncan ha señalado que la oposición entre lo público y lo privado está regida por el discurso filosófico, político, legal y popular. Duncan sostiene que esa oposición binaria ha sido empleada para legitimar la opresión y la dependencia de la mujer basadas en la diferencia genérica (I27). Es más, el espacio privado se ha asociado con lo doméstico, lo natural, lo corporal, la pasión, la sexualidad, la familia y la propiedad mientras que para el espacio público se ha reservado lo incorpóreo, lo abstracto, lo racional, lo cívico, la sociedad civil, la producción, la ley, la polis y el Estado (Duncan I28). En "Decente", la pelirroja ha violado la regla no escrita de permanecer en el espacio público del parque y ello da pie a que Condorito le proponga que tengan un amorío. Si se sigue la tradición hispánica, a esa hora, la mujer debería estar en su casa, en el espacio privado que se le ha asignado a ella, porque de no ser así, se la podría catalogar de indecente o muy posiblemente de una mujer pública. ${ }^{2}$

Duncan analiza la diferencia semántica que existe en el discurso de Occidente entre un hombre público y una mujer pública: "Because of women's traditional exclusion from the political sphere, the term 'public woman' in dominant discourse has traditionally meant 'not respectable', a prostitute, whereas a public man was a statesman" (139). Es decir, al hombre público se lo respeta porque detenta un alto cargo político y tiene el control sobre el Estado. Sin embargo, la mujer pública se asocia con la prostituta, la mujer cuyo cuerpo es un espacio controlado por varios hombres. Su trabajo se desempeña normalmente en las calles donde consigue a sus clientes, pero los encuentros sexuales se dan generalmente en el espacio privado de los burdeles. La mujer respetable debe ante todo servir a un solo hombre en términos sexuales. En la historieta titulada "Decente", es evidente que la chica quiere establecer que, a pesar de estar en un parque público, ella es una mujer respetable que no está dispuesta a tener un romance pasajero con Condorito.

Ahora bien, si Condorito tiene un papel marginal en "Decente", hay un cambio en el sentido de lugar del personaje y por ello cambia su caracterización a través de las historietas, ya que en muchas otras tiras se desempeña en posiciones de autoridad como juez, gerente, médico o farmaceuta. Por lo tanto, se mueve con facilidad en los espacios citadinos 
que controla, y es respetado en sitios como la corte, las empresas, los hospitales, las farmacias o los cafés. Curiosamente, en ellos Yayita y todas las otras mujeres con las que interactúa tienen una posición subalterna y se muestran como figuras hipersexualizadas. Rebecca Collins ha estudiado la manera en que las mujeres han sido representadas en los medios masivos de comunicación. Para Collins existe una gran disparidad en la representación de las mujeres con relación a los hombres y dicha diferencia ha persistido durante varias décadas entre I950 y 2009. En su estudio, la investigadora agrega que cuando se las representa: "Women are often sexualized-typically by showing them in scanty or provocative clothing. Women are also subordinated in various ways, as indicated by their facial expressions, body positions, and other factors. Finally, they are shown in traditionally feminine (i.e., stereotyped) roles" (290). Como hemos visto en "Decente" y como demostraremos en el análisis de otras historietas de Pepo, los aspectos que señala Collins como característicos de la representación femenina en los medios corresponden, punto por punto, con la manera en que se perfilan los personajes femeninos en Condorito.

Este es el caso de la tira titulada "Vuelta" (fig. 2), en la cual Condorito hace el papel de un médico que atiende en su consultorio a una chica que padece un dolor de estómago. La imagen de la mujer joven es hipersexualizada, ya que ella aparece con un traje corto que deja ver sus prominentes senos, su pequeña cintura y sus largas piernas. Ante la solicitud del médico Condorito de que se quite la ropa, la chica exige que se dé la vuelta. Sin embargo, Condorito opta por pararse de manos para observar mejor el cuerpo desnudo de la paciente. La incongruencia de sus acciones y sus comentarios producen la risa para una audiencia típicamente masculina. Sin embargo, un análisis más profundo del texto pone de presente que persiste un interés constante por ejercer poder y control de los espacios y los cuerpos femeninos por parte de Condorito. Dicho poder no cede a pesar de los intentos de la paciente de manejar la situación al pedirle que no la observe mientras se quita la ropa.

En términos de los aspectos genéricos que implica la distinción entre lo público y privado, el episodio representado en "Vuelta" refuerza la idea de que, en algunos casos, los espacios privados como el hogar o el consultorio médico reducen la libertad de la mujer y se convierten en lugares peligrosos. Si bien la clínica está en un sitio público, el consultorio médico es un espacio privado que funciona, en este caso, en forma similar al hogar. Como lo señala Duncan:

Paradoxically the home which is usually thought to be gendered feminine has also traditionally been subject to the patriarchal authority of the husband and father. 
Personal freedoms of the male head of household often impinge on, or in extreme cases, negate the rights [and] ... safety of women ... who ... occupy these spaces. (I3I)

En la tira "Vuelta", la paciente femenina que solicita ayuda del médico se encuentra bajo el poder patriarcal del facultativo, quien hace evidente sus apetitos sexuales, porque se sugiere que está más interesado en satisfacerlos que en curar el mal que aqueja a la paciente.

Si bien los centros de asistencia médica no resultan positivos para los personajes femeninos en Condorito, tampoco lo son las empresas. En la historieta "Puesto" (fig. 3), una chica va a una compañía a solicitar un empleo. Al igual que en las tiras anteriores, la hipersexualización del personaje femenino es evidente. La candidata al puesto de secretaria está representada como una mujer de cabello largo, alta y voluptuosa. El primer cuadro presenta a la chica desde la perspectiva de Condorito, punto de vista que podría coincidir en gran medida con el de los lectores masculinos de la historieta. Condorito observa que ella está vestida con una blusa roja muy pegada al cuerpo, que revela sus grandes pechos, y una minúscula falda negra que, como en representaciones anteriores, deja ver sus largas piernas, su pequeña cintura y su gran cadera. La figura de la candidata al trabajo domina totalmente el cuadro. En contraste, Condorito, ubicado en la parte izquierda del panel, está vestido de manera muy formal con una corbata negra y una camisa roja, y trabaja como empleado en la firma.

Condorito le pregunta a la candidata a la vacante: “¿En qué puedo ayudarla?" (Pepo 45.615), y ella responde que viene "por el puesto de secretaria" (Pepo 45.615). Contrario a lo que es normal en una situación de trabajo, Condorito no le pide que le deje su curriculum vitae sino sus medidas, así que se refiere a las dimensiones del busto, la cintura y la cadera. Sin embargo, dicha respuesta revela un código cultural muy persistente en la cultura hispánica tradicional: la idea de que no es importante el conocimiento que tenga la candidata para realizar su trabajo, sino sus atributos físicos. Es decir, el intento de la joven de ejercer una actividad productiva en el espacio público en un oficio que implica más el intelecto que el cuerpo se halla frustrado dado el patrón cultural que mide las habilidades de las mujeres en términos de sus cualidades físicas. La historieta parece sugerir que el espacio público de los negocios está vedado a las mujeres, a menos que ellas estén dispuestas a poner su cuerpo al servicio de los gerentes.

Para Doreen Massey, la relación de los individuos con los espacios y las relaciones de poder determinan su sentido de lugar, el cual tiene un impacto en los papeles genéricos (5). Como hemos visto en las tiras de Condorito, es evidente que a pesar de los intentos de las mujeres de salir al espacio 
público o de conseguir un empleo en una compañía, las relaciones de poder impiden que este objetivo se lleve a cabo completamente, y la mujer es forzada a desempeñar el mismo rol que le ha sido asignado tradicionalmente: servir al hombre tanto en el espacio público como en el privado. Para mujeres como la candidata a secretaria, trabajar en el espacio público no implica adquirir un nuevo sentido de lugar sino más bien reforzar el que ha tenido por siglos. Es decir, para las mujeres representadas en Condorito conquistar la ciudad desempeñándose en carreras profesionales no es una verdadera opción. La representación de los personajes femeninos en Condorito corresponde a una visión tradicional ya que generalmente ellas realizan oficios como amas de casa, esposas, madres o empleadas domésticas.

La única excepción a esta tendencia de representar a las mujeres hipersexualizadas en el espacio público es posiblemente el número $5 \mathrm{I}$ del 2006 , que presenta en la portada la imagen de Yayita como si fuera la presidenta de la república en un desfile (fig. 4). La fecha de este número de Condorito coincide con la elección de Michelle Bachelet como la primera mujer presidenta de Chile en 2006. En esta portada de Condorito, Yayita está vestida de blanco y luce la banda presidencial al igual que lo hiciera Bachelet durante su posesión como mandataria del país el ir de marzo de 2006. Condorito conduce el vehículo mientras que Yayita está de pie saludando. El auto está rodeado de una escolta de militares a caballo que la sigue. Ésta es una de las pocas historietas en las cuales Condorito observa con admiración a Yayita, la mujer que representa a Michelle Bachelet. También se destaca la actitud del soldado que saluda militarmente a la presidenta creando así un nuevo sentido de lugar para a la mujer en Condorito, aunque este resulte efímero.

La escritora chilena Diamela Eltit analiza el significado de los signos culturales de la sociedad chilena contemporánea y los cambios que se operaron en el país a raíz de la elección de Michelle Bachelet en 2006. Eltit celebra que Bachelet hubiera elegido un gabinete paritario en el que hubo igual número de mujeres que de hombres por primera vez en la historia política de Chile. Según Eltit, dicha decisión fue motivada porque Bachelet, a pesar de haber logrado trabajar con éxito en varios ámbitos del espacio público, tuvo que enfrentar "la tradicional discriminación de la mujer en la esferas pública y privada" (156). Al referirse a los obstáculos que tuvo que superar, Eltit afirma que: "Mi hipótesis es que Bachelet, por su comprensión de los códigos, pudo habitar (soportar) esos lugares, pero cuando fue elegida presidenta de la República su gran gesto y su gran gesta fue escenificar lo que ha sido históricamente la gran demanda de un sector del feminismo: la igualdad de género" (156). La escritora hace un excelente 
trazado de los espacios que Bachelet tuvo que conquistar y de los esfuerzos que hizo durante su gestión para aumentar la participación de la mujer en la vida pública. Es decir, Eltit reconoce que: "Culturalmente, Chile ... está estructurado bajo los signos convencionales de un machismo sin muros de contención" (156).

Ahora bien, dado este retrato que hace Eltit de la sociedad chilena sitiada por el machismo, no sorprende que los esfuerzos por realizar cambios sean muy tímidos en Condorito. Si bien la portada del número publicado el 8 de septiembre de 2006 es un obvio homenaje a la elección de una mujer como la primera presidenta de la nación, el contenido de la revista no presenta el relato gráfico de cómo llegó Yayita a ejercer el poder político. Desafortunadamente, las historietas que contiene la revista continúan representando a las mujeres en papeles tradicionales relacionados con la familia en el espacio privado, o dedicadas a la enseñanza de los niños o velando por los enfermos en sitios públicos como los hospitales.

Massey postula que el sentido de lugar no es una noción fija, sino que cambia con el paso del tiempo, debido a las influencias externas, a las negociaciones identitarias que se operan en la sociedad y a factores como la globalización (178). Como bien lo ha documentado el sitio web Memoria chilena, el personaje de Pepo ha sufrido cambios en su representación gráfica a través del tiempo: "Condorito experimentó una paulatina transformación en las páginas de la revista Okey. La manta y el plumaje del cuello desaparecieron y su aspecto se fue volviendo cada vez más humano. El pico alargado se acortó y las facciones del rostro fueron redondeadas". Dicha evolución no solamente tiene que ver con los cambios antropomórficos sino también con el sentido de lugar que se da a la figura de Condorito. Al respecto, Poblete afirma que: “Condorito's appearance, half way between a condor (one of Chile's national symbols) and a human, allows the character to perform an implicit critique, a defamiliarization or, at least, a performatic deployment of many of the social codes constituting modern life" (48). A pesar de ser una figura mitad pájaro y mitad humano, el personaje de Pepo se transforma de ser representado como el roto de origen campesino que vagabundea por la ciudad, a un sujeto respetado cuando se presenta como gerente, médico o juez en otros sitios como las compañías, los hospitales o la corte.

¿Podría pensarse que la crítica implícita a los códigos sociales a la que alude Poblete se extendiese a la conducta de una parte de la población masculina tanto en Chile como en Latinoamérica? Es posible, dado que las historietas exponen un comportamiento masculino que quizá la mayoría de la sociedad reproche. Me refiero a que, a través del protagonista de 
Condorito, se representan esas conductas masculinas que convierten a la mujer en objeto del deseo, situación que es evidente en "Decente", "Vuelta" y "Puesto". Henri Bergson arguye que lo cómico expresa "cierta imperfección individual o colectiva que exige una corrección inmediata. Y esa corrección es la risa" (36). Ello explicaría la razón por la cual tanto Pepo como los guionistas contemporáneos revelan, por un lado, ese tipo de comportamientos masculinos que requieren un cambio de conducta (representar a las mujeres desnudas), y por el otro, hacen gran uso del tempo narrativo e interrumpen la narración. Es decir, Pepo no presenta el cuerpo desnudo de los personajes femeninos en los cómics, sino que interrumpe el relato visual con el distintivo ¡Plop! cuando los lectores piensan que va a aparecer la chica desnuda.

Ahora bien, a pesar del alcance crítico de la sociedad y la cultura chilena que se logra en Condorito, la caracterización de las figuras femeninas parece haberse congelado en el tiempo. Es decir, la capacidad crítica del personaje parece circunscribirse a las taras de la sociedad moderna, pero su alcance no llega a transformar radicalmente el papel de la mujer. A través de todas las historietas, las mujeres se enfocan generalmente a realizar tareas domésticas en el espacio privado y están dedicadas al cuidado de los niños y de los enfermos en el espacio público. Esta tendencia a reafirmar parámetros tradicionales con respecto al papel de la mujer en la sociedad sorprende ya que los derechos para las historietas, originalmente creadas por Pepo, fueron vendidos en 1976 a Editors Press Service de los Estados Unidos. Las historietas fueron sindicalizadas, y en 1993 los derechos fueron adquiridos por Televisa Internacional, la multinacional mexicana. No obstante, tal pareciera que el nuevo equipo editorial, en lugar de realizar cambios en la representación del sujeto femenino acordes con la transformación social que ha sufrido Latinoamérica, no considerara que esa fuese una opción rentable. ${ }^{3}$ Es evidente que, en el mundo de hoy, hay un incremento notable en la participación de la mujer en el espacio público que está lejos de ser representado en Condorito, una de las historietas latinoamericanas más leídas en todo el mundo.

En Mafalda, otra de las historietas latinoamericanas de gran éxito mundial, la distinción entre el espacio público y el espacio privado es evidente. Las tiras ponen en tela de juicio los modelos de feminidad, ya que problematizan el sentido de lugar de la mujer y los papeles genéricos, cuestionamiento que no se da en Condorito. Mafalda fue creada por Joaquín Lavado, conocido como Quino, para una campaña publicitaria de los electrodomésticos Mansfield de la compañía Siam Di Tella en i964. Según Isabella Cosse, la campaña debía incluir la historia de una familia bonaerense típica, que constara de la madre, el padre y dos hijos. El modelo 
a seguir era la tira sindicada Peanuts de Charles M. Schulz (2I). El nombre de cada uno de los personajes tenía que empezar con M, por lo cual Quino se inspiró en los personajes de la película Dar la cara (1964).4

La abundante crítica que se ha publicado sobre la obra de Quino parece distribuirse en tres grupos. Por un lado, están los que analizan a Mafalda desde el punto de vista artístico, como Oscar Masotta. Por otro lado, están quienes han explorado los contenidos ideológicos y de representación de los imaginarios como el de la nación, la identidad nacional o la relación con la política como Héctor Fernández L'Hoeste, David Foster y Umberto Eco. Un tercer grupo está constituido por quienes analizan la construcción de la feminidad como Brittany Nicole Tullis o el impacto o subversión de los parámetros de género como Isabelle Cosse. El libro de esta última es quizás uno de los más completos e innovadores, ya que no solamente ha hecho un gran trabajo de documentación, sino que también se centra en analizar el fuerte impacto generacional de Mafalda en la consolidación o subversión de parámetros de género. Mi investigación se nutre en muchos aspectos de la crítica existente, pero aporta una nueva dimensión ya que ninguno de los críticos mencionados establece la relación entre las construcciones de género y los espacios en Mafalda.

Mafalda es una niña de unos 6 o 7 años que sorprende a todos con sus ocurrencias. Las tiras de Mafalda se componen de cuatro o cinco paneles que siguen la estructura clásica descrita por Resnick y Speck: "first, a disruption of equilibrium, with the emergence of a conflict or incongruity; second, a sharpening of the conflict, peaking in a crisis or climax; and third, a resolution of dénouement, leading to a new equilibrium on different terms from those of the original situation" (79). En los dibujos se representan las aventuras de la niña, sus conexiones con varios personajes entre ellos sus padres, su hermano Guille y sus amigos: Manolito, Felipe, Miguelito, Susanita, Muriel y Libertad. 5 En contraste con Condorito, en Mafalda no se utiliza el color sino solamente el blanco, el negro, las sombras, las expresiones faciales de los personajes, el juego con los ángulos y los espacios en on y en off. La tira nunca fue sindicalizada, ya que Quino inició la serie en I964 y dejó de dibujarla en I973. Además, las tiras de Mafalda tampoco llevan título como ocurre en Condorito.

Como sostiene Umberto Eco, Mafalda se caracteriza por su actitud contestataria contra las normas sociales (6). Isabella Cosse amplía esa noción al argüir que dicha conducta contestataria corresponde a la que caracteriza a la generación de los años sesenta, cuando los jóvenes en todo el mundo protestaban contra las injusticias sociales, la falta de equidad económica, la guerra del Vietnam, la carrera armamentista, las desigualdades de género y los sistemas políticos represivos, entre otros 
muchos temas. Debemos recordar que los años sesenta fueron la época de los grandes movimientos estudiantiles a ambos lados del Atlántico como el de París o el de Tlatelolco en México en i968. Parte de esa rebelión se presenta en la tira a través de la relación compleja entre Mafalda y Raquel, su madre. Mafalda enfrenta no solamente la autoridad que ella representa, sino que también cuestiona mediante la ironía y las actividades que Raquel realiza como ama de casa tradicional en la esfera doméstica en la que opera.

En las tiras que analizaremos a continuación veremos cómo Mafalda desestabiliza el sentido de lugar de la mujer asociado al espacio privado. Como lo ha documentado ampliamente Brittany Nicolle Tullis, en los años sesenta el ideal de feminidad se construía alrededor de la imagen de la mujer como el ángel del hogar (I66). ${ }^{6}$ Dicha construcción se enfatizaba a través de los medios masivos de comunicación como las revistas de publicación mensual. Isabella Cosse analiza la importancia de esta idea en el imaginario nacional argentino en revistas populares como Claudia, publicación en la cual se destacaba que la mujer moderna debía representar el papel de la mujer que está a cargo de las tareas domésticas y funge como una excelente madre y esposa. Es decir, el lugar de la mujer estaba definido por la actividad doméstica que realizaba en espacio privado del hogar. No obstante, dicho modelo genérico se desvirtúa en Mafalda en tiras como la I40 y las publicadas en Primera Plana.

Como lo afirma Tullis, en las primeras cuarenta y ocho tiras de Mafalda publicadas en Primera Plana en 1964, Raquel se representaba siempre en el espacio hogareño realizando tareas domésticas como lavar, cocinar, limpiar o quitar el polvo. No obstante, otra faceta interesante que revelan estas viñetas es que inclusive el espacio mismo de la casa se encuentra asociado a las distinciones genéricas. En el artículo "Untitled: The Housing of Gender", Mark Wigley explica cómo desde el renacimiento los espacios estaban destinados para uno u otro sexo dependiendo del papel que hombres y mujeres desempeñaran en la sociedad. Para las mujeres estaban asignados sitios como la cocina y el cuarto de los niños mientras que el despacho del hombre era un espacio intelectual en el que la mujer no podía entrar (332).

En las tiras publicadas en Primera Plana así como en las que aparecieron en El Mundo a partir de 1965, es frecuente encontrar que el padre de Mafalda ocupa espacios como el escritorio donde realiza las cuentas o la sala donde lee el periódico. Tanto dichos espacios como las actividades que hace parecieran ser exclusivas del rol del padre. En contraste, se sugiere que el reino de la madre está reducido a la cocina y al patio de ropas, sitios en los cuales Mafalda increpa a Raquel por realizar los oficios domésticos y no tener una carrera profesional. Por el contrario, Mafalda discute con su padre en la sala temas de interés mundial como los 
asuntos políticos (tira 356), el desarme nuclear (tira 454) o la superpoblación mundial (tira 218). Curiosamente, Mafalda se desenvuelve en todos los espacios de la casa y tiene la opción de entrar y salir de ella cuando quiere. En este sentido, la niña parece gozar de tanta libertad para moverse en los espacios públicos y privados como Condorito, a pesar de su corta edad y de su género.

Al respecto, Isabella Cosse sostiene que una de las claves de la vigencia de Mafalda ha sido la contradicción entre la edad biológica (entre los 4 y los 7 años) y la edad intelectual del personaje. Mafalda se construye en la ambigüedad entre la adultez y la niñez y lo masculino y lo femenino. Según Cosse: "En términos de género, Mafalda -el personaje- jugó con ciertas ambigüedades u oscilaciones andróginas" ("Ese monstruito" 1553). Para la investigadora uruguaya, la androginia se basa en la caracterización del personaje, ya que en las primeras tiras publicadas en Primera Plana se juega entre actitudes que se consideraban netamente masculinas, como el uso de las malas palabras y la picardía, y cualidades asociadas con lo femenino, como la ternura y la comprensión. Todo ello se reforzaba por medio de los rasgos agresivos del personaje como la expresión facial del enojo (el ceño fruncido y la boca muy abierta).

En mi opinión, no se trata tanto de una androginia sino más bien de un intento de promover la idea de que necesario que la mujer conquiste espacios tales como el ágora para la discusión política o las instituciones del Estado, que, como señala Nancy Duncan, le habían sido vedados. Quino es en verdad un hombre avanzado para su época porque, dada la rebelión de su personaje estrella, es patente que consideraba que era necesaria la participación de la mujer en el espacio público. También vale destacar el uso de estrategias gráficas muy innovadoras ya que consigue subvertir los parámetros de género desde el espacio privado del hogar. Veamos por ejemplo lo que ocurre en la tira I4O (fig. 5), en la que Mafalda es conminada por su madre a que le ayude a limpiar el polvo, un oficio que las mujeres hacen a diario en sus hogares. Mafalda parece emular a su madre en el atuendo al ponerse un delantal y un pañuelo en la cabeza, lo que podría indicar que ella está dispuesta a seguir el modelo de domesticidad de la madre. Raquel le pide que le pase el plumero al globo terráqueo y Mafalda accede, pero le pregunta: “Limpio todos los países, o solo los que tienen malos gobiernos?" (Quino 8I). Mientras que Raquel le da un sentido literal a la noción de quitarle el polvo al objeto que representa el planeta tierra, el humor surge cuando Mafalda le otorga un significado más figurado que tiene que ver con luchar contra la corrupción o las malas administraciones de algunos países. Al hacerlo, Mafalda desafía el modelo del hada de hogar que le inculca su madre y se ubica en una alta posición política, legal y ética 
para poder llevar a cabo la tarea de limpiar a los gobiernos corruptos. Es decir, en contraposición a Raquel, quien sigue operando en el ámbito privado del hogar, a través de ese chiste, Mafalda desequilibra el modelo genérico femenino y se imagina a sí misma en las altas esferas del poder político o judicial.

La subversión del modelo de género transferido de madre a hija y el juego con los espacios públicos y privados también se hace patente en la tira I389 (fig. 6). En los tres primeros paneles, Mafalda sigue de cerca el trabajo de limpieza que hace su madre barriendo debajo de la cama en una habitación, recogiendo la basura en la cocina y lavando la ropa en el patio. Un acercamiento extremo, casi cinematográfico, nos presenta en el cuarto panel la cara de perfil de Mafalda quien inicia la primera frase de una pregunta difícil: "La capacidad de triunfar o fracasar en la vida...", la cual se completa en el quinto panel: “¿Es hereditaria?" (Quino 396). Tanto los recursos gráficos como lingüísticos utilizados en la tira 1389 coadyuvan a fracturar el modelo tradicional del sentido de lugar de la mujer asociado al trabajo doméstico y al espacio privado. El representar el rostro de perfil de Mafalda en el tercer cuadro se acentúa gráficamente la idea de que la hija podría seguir el modelo de vida de la madre. Por otro lado, las letras temblorosas y el globo de texto trazado con líneas en curvas sucesivas en el quinto panel subrayan el temor que sufre la protagonista de tener que emular el patrón genérico trazado por Raquel, lo que representaría algo que Mafalda percibe como el fracaso en la vida.

Tanto el uso del lenguaje corporal como los ángulos utilizados en esta tira refuerzan la crítica al modelo del hada del hogar. La expresión facial de Mafalda ante el oficio doméstico realizado por Raquel comunica la idea de que la niña considera que permanecer en el espacio privado haciendo tareas domésticas implica una frustración total para la mujer.7 El ángulo oblicuo utilizado por Quino en la tira ${ }_{1389}$, que muestra en la parte próxima al espectador tanto el rostro sorprendido de Raquel ante la pregunta de su hija como la imagen empequeñecida de Mafalda arrinconada en una esquina del patio de ropas en el quinto panel, desequilibra la noción tradicional de que las hijas deben imitar el camino trazado por sus madres. Curiosamente, la escena tiene lugar en el patio de ropas o en un balcón, un sitio limítrofe entre el espacio de adentro de la casa (lo privado) y el espacio de afuera (lo público); así que este uso sorprendente del espacio y los ángulos en la tira promueven la desarticulación de la construcción de lo femenino asociada al espacio privado del hogar.

Héctor Fernández L'Hoeste asegura que la caracterización unidimensional de Raquel como solamente una ama de casa relegada a la esfera del hogar limita el potencial del texto para realizar una crítica 
feminista sólida ("From Mafalda to Boogie" 86). Aunque esa aseveración pudiera ser acertada para el caso de Raquel, es evidente que Quino utiliza el contraste de la representación de la madre de Mafalda con otro modelo de feminidad que desafía tales premisas. Se trata de la madre de Libertad. Esta última es un personaje que se introduce en las tiras de Mafalda el is de febrero de 1970. En la tira I33I (fig. 7), Libertad convida a Mafalda a jugar en su apartamento. Mientras que Raquel, la madre de Mafalda, representa siempre el papel del hada del hogar dentro del espacio doméstico y se la ve frecuentemente limpiando y arreglando armarios, Quino utiliza el contraste con la madre de Libertad para mostrar otro modelo de feminidad: el de la mujer intelectual. Las tiras I33I, I332 y I334 revelan que la madre de Libertad es traductora profesional.

La parte gráfica de la tira I33i subraya la diferencia en modelos genéricos femeninos ya que a través de la utilización de un ángulo en picado y la distribución de los espacios en on y en off se destaca que la madre de Libertad trabaja frente a su máquina de escribir y rodeada de estantes de libros. ${ }^{8}$ El paralelismo que se observa en el quinto panel entre la conversación que tienen las niñas en el vestíbulo y la actividad que desarrolla la madre en su oficina evoca la dinámica que se establece a través del uso del ángulo oblicuo en la tira 1389. Mientras en la tira 1389 se subrayaba que Mafalda, a pesar de sus temores, podría emular a su madre y convertirse en hada del hogar, en la tira 1332 se abre la posibilidad a que las niñas Mafalda y Libertad sigan el nuevo modelo de la mujer intelectual.

Otro aspecto interesante que surge al contrastar la tira 1389 y la 1332 tiene que ver con los resultados del trabajo que realiza Raquel como ama de casa y la madre de Libertad como traductora y con la remuneración que reciben. Si Raquel cocina, plancha la ropa y, según el chiste que hace Mafalda en la tira I335, podría ser "dueña de una polvareda" (Quino 383) porque se dedica a barrer y a aspirar la casa, la madre de Libertad, en cambio, traduce libros del francés al español, como los escritos de Jean Paul Sartre (tira 1332). El juego de palabras con la palabra "sastre" en español y Sartre en francés (ya que Libertad no puede pronunciar correctamente el apellido del filósofo), así como el identificar el libro de Sartre como “iÉse! El último pollo que comimos lo escribió él", nos remite de nuevo a la diferencia en el sentido de lugar de cada una de las mujeres (Quino 383). Si bien Raquel prepara sopas, comida que detesta Mafalda, la madre de Libertad, por su parte, traduce un "pollo" (Quino 383) escrito originalmente por Sartre. La metáfora culinaria sirve para subrayar las diferencias porque la sopa alimenta al cuerpo y el pollo (el libro de Sartre) nutre al intelecto. Por otra parte, Libertad comenta que su madre también mantiene la casa porque: "lo que gana mi Papá es para pagar el departamento" (Quino 383). Además, su 
trabajo de traducción se publica, a pesar de que no es bien pagado. En contraste, resulta evidente que el arduo trabajo doméstico que realiza Raquel no es ni apreciado ni remunerado, y su esposo es quien provee todo el dinero para los gastos del hogar.

En los textos periodísticos que aparece en Toda Mafalda, Judith Gociol comenta que en las tiras publicadas en la revista Primera Plana, "Las referencias que se hacen en las tiras a China, África, América Latina y la condición femenina tienen que ver con que, por entonces, se creía firmemente en que el Tercer Mundo y la mujer lograrían revertir su situación de sumergidos" (538). Esa idea de transformar la posición de la mujer es evidente en Mafalda, y ya hemos visto cómo los paralelismos entre madres e hijas y los recursos gráficos empleados por Quino incitan a la desestabilización del papel del hada del hogar a favor del modelo de la mujer intelectual que se desenvuelve tanto en el entorno privado como en el público. Otra estrategia utilizada para propiciar la participación activa de la mujer en el espacio público la constituyen los juegos infantiles como el del gobierno que se presenta en las tiras que Quino publicó en el periódico $E l$ Mundo de Buenos Aires entre 1965 y 1967.

Según Gociol, el diario El Mundo era "uno de los más populares e independientes" de la capital argentina (552). Ello explicaría la razón por la cual las tiras de Mafalda retan al sentido de lugar de la mujer en la Argentina al proponer, en las once tiras publicadas entre el Io de mayo y el I4 de junio de 1965 , que ella sea presidenta. El momento en que se publicaron dichas tiras coincide con la crisis del gobierno de Arturo Umberto Illia, que culminó con el golpe militar del 28 de junio de 1966. En un ambiente de aparente vacío de poder, es muy significativo que Mafalda y sus amigos jueguen al gobierno y que Mafalda se autoproclame como la candidata para ejercer la primera magistratura del país. El proceso de auto-nominación de Mafalda empieza en la tira del io de mayo en la que Mafalda lanza la idea de que jueguen al gobierno. En el primer panel, Manolito se autonombra como ministro de finanzas. En los siguientes tres cuadros, Felipe acepta renuentemente ser el ministro de relaciones exteriores. En la tira del ir de mayo (fig. 8), Manolito rechaza fuertemente la idea de que Mafalda sea presidenta aludiendo que es: “iAbsurdo! ¡Una mujer no puede ser presidente!" a lo que Mafalda replica que es preciso "innovar" (Lavado 554). Tanto las expresiones faciales de Manolito y Mafalda como la ubicación de ellos frente a frente en el panel evidencian los dos lados de la controversia. Ambos argumentos se presentan en letras en negrilla entre signos de exclamación destacando la virulencia del enfrentamiento entre las visiones a favor y en contra de que la mujer ejerza un puesto público de tal envergadura. 
Las tiras publicadas en El Mundo proveen la historia completa de la carrera de Mafalda hacia la presidencia en el juego del gobierno. Mientras que inicialmente, en la tira del II de mayo, Manolito rechaza que Mafalda sea la presidenta, en la del 13 de mayo, Felipe trata de convencerlo de que acepte que Mafalda asuma ese papel. Más tarde, en la tira del I4 de mayo, Mafalda plantea que haya un triunvirato en el que todos tengan el mismo poder. Aquí el chiste surge porque Manolito le plantea a Felipe que: "vos y yo formemos un biombo" (Lavado 555). Claramente, se detecta que ésta es una crítica a las luchas del momento entre los partidarios del general Juan Carlos Onganía y los seguidores de Juan Domingo Perón, quien todavía estaba en el exilio en España. En términos de estrategias gráficas, se destaca que, en varias de estas tiras, Mafalda se encuentra sentada en el centro del cuadro entre sus amigos Felipe y Manolito, y ella es quien dirige la discusión y propone las ideas. Esto es particularmente evidente en la tira del I7 de mayo en la que, una vez ha sido aceptado que Mafalda es la presidenta, se involucran en una discusión que concluye en el cuarto panel con los tres amigos sentados en la acera pidiendo limosna. Obviamente, esta es una clara referencia al momento de negociación de la deuda externa con el Fondo Monetario Internacional, que dio pie "a la campaña orquestada contra la gestión del gobierno" de Illia por parte del peronismo (Gociol 553).

En Mafalda, la representación de la protagonista como la presidenta presenta un claro contraste con lo que ocurre en Condorito. Como lo analizamos anteriormente, la portada de la revista 5I de Condorito muestra a Yayita como presidenta, haciendo un claro homenaje a la elección de Michelle Bachelet como la jefe del Estado chileno en 2006. Sin embargo, la revista en sí no hace la narración gráfica del ascenso del personaje a la primera magistratura del gobierno ni de cómo lleva a cabo esta tarea. En realidad, a Yayita nunca se la muestra postulando a esa posición ni leyendo un discurso político porque realmente su caracterización en toda la historieta no encaja con el papel de líder política del país. Ella se representa primordialmente como el hada del hogar en la residencia paterna o en la casa de Condorito cuando se casa con él. En contraste, Mafalda presenta todo un relato gráfico del proceso que sigue la protagonista de la tira para llegar a ejercer este alto cargo en el juego del gobierno. En dicho juego, es Mafalda quien lanza las ideas innovadoras y ejerce el poder. Esta forma de representar a Mafalda deja ver claramente que en el cómic promueve la desestabilización del status quo y la noción de que no existe democracia sin incluir la posibilidad de que las mujeres lideren el Estado. Es por ello que Mafalda conspira con sus amigos en el espacio privado y se toma el espacio público con su gabinete para poder enfrentar los retos económicos del país. 
En suma, el análisis de Condorito y Mafalda nos ha permitido explorar a la luz de los conceptos de Doreen Massey y Nancy Duncan cómo la representación de los personajes femeninos en las historietas de Pepo y Quino refuerzan o subvierten los papeles genéricos y el sentido de lugar de acuerdo con los espacios que las mujeres ocupan en la sociedad. En Condorito, la caracterización y la hipersexualización de los personajes femeninos fomentan el modelo tradicional de la mujer como un sujeto que atiende las necesidades masculinas, tanto en el espacio público como en el privado. En contraposición, en Mafalda, una novedosa utilización de estrategias gráficas como los ángulos cinematográficos y los espacios cuestionan, desde el espacio privado, el papel tradicional de la mujer como el hada del hogar y presentan la alternativa de la mujer intelectual. A pesar de los leves intentos de Condorito por proponer un modelo nuevo para la mujer latinoamericana con su portada de Yayita como presidenta de Chile, la construcción del sentido de lugar de la mujer parece haberse fosilizado al representarla en la mayoría de sus historietas como carente de agencia y en peligro constante por tratar de conquistar el espacio público. Por el contrario, Mafalda mantiene su actualidad, ya que en dicho cómic se socava este patrón genérico al utilizar el juego del gobierno para representar una Mafalda negociando eficazmente con las representaciones de género tradicionales y ejerciendo el poder político. Aunque, como sostiene Isabella Cosse, Quino nos presenta a una niña intelectual que parece que nunca crece en los nueve años que publicó Mafalda, su labor en la desestabilización del modelo genérico femenino tradicional y la conquista del espacio público han allanado el camino para las propuestas creativas de la nueva generación de artistas como Maitena Burundarena o Adriana (Nani) Mosquera.

University of Calgary

\section{NOTAS}

I En Comic Relief: A Comprehensive Philosophy of Humor, John Morrell propone tres teorías para explicar el humor: la superioridad, la incongruencia y el humor como válvula de escape. Con respecto a la incongruencia, Morrell afirma que todo comentario o acción que carezca de lógica, armonía, compatibilidad o consistencia produce irremediablemente el humor (II). Siguiendo el pensamiento de John Morrell, en este caso el comentario de Condorito es incongruente porque la silla del parque no es realmente propiedad de Condorito. 
2 La asociación de la mujer hispánica con el hogar ha sido una característica constante en tradición española y latinoamericana. Al respecto, la investigadora Ángeles Cantero Rosales, en su artículo “De 'Perfecta casada' a 'Ángel del hogar' o la construcción del arquetipo femenino en el siglo XIX", ha trazado el sentido de lugar de la mujer asociado al espacio privado de la casa y la domesticidad. A partir de ensayos como La perfecta casada (1583) de Fray Luis de León y La familia regulada (1715) de Fray Antonio Arbiol, Cantero demuestra que los frailes impulsaron la idea que la mujer debía permanecer encerrada en casa, entregada a labores como cocinar, tejer y organizar a los sirvientes dada su debilidad física, mientras que para los hombres se reservaba el espacio público. El concepto de hada del hogar fue desvirtuado por Concepción Arenal (La mujer de su casa, I88I) y escritoras como Emilia Pardo Bazán en España. En Latinoamérica, la colombiana Soledad Acosta de Samper desestabilizó el modelo del ángel del hogar tanto en sus novelas (Dolores y Una holandesa en América) como en sus ensayos (Aptitud de la mujer para ejercer todas las profesiones, 1892). En el siglo XX, la escritora mexicana Rosario Castellanos también desvirtúa dicho modelo en ensayos (Mujer que sabe latín, 1973) y en sus cuentos (Álbum de familia, 1971). Nicole Villagra señala que cuando se venden los derechos a Televisa Internacional en I993, el tiraje de Condorito alcanza los I4 millones de ejemplares vendidos en toda Latinoamérica. Televisa no solamente vende revistas, sino que también publica videos en el sitio oficial de condorito.com en los cuales los personajes femeninos son hipersexualizados y realizan trabajos tradicionales como amas de casa o enfermeras al igual que ocurre en las tiras impresas. Ejemplo de ello es el video titulado "Letrero" de 20 I9 en el cual se presenta a la mujer como un objeto sexual. Dicha representación es muy similar a la de la tira titulada "Inflable" (52.045) publicada doce años antes. En el ejemplar del 24 de julio de 2007 la mujer es una muñeca que desempeña el papel de compañera sexual de Condorito. Tanto en el video como en la tira 52.045, los personajes que dialogan son Condorito y Cabellos de Ángel.

4 Dar la cara fue una película dirigida por José Martínez Suárez inspirada en la novela de David Viñas que lleva el mismo título. Se estrenó en Buenos Aires el 29 de noviembre de i962. El libreto fue escrito por Martínez Suárez, y Viñas colaboró en el proyecto. La película fue protagonizada por Leonardo Favio, Luis Medina Castro, Pablo Moret y Nuria Torray. En el filme aparece un bebé llamado Mafalda, nombre en el cual se inspiró Quino para bautizar a la protagonista de su tira.

$5 \quad$ Los amigos de Mafalda se caracterizan de diversas maneras. Manolito Goreiro es hijo de un inmigrante gallego que establece una tienda de barrio. A Manolito le interesa el dinero sobre todas las cosas y busca maneras de mejorar el negocio de su padre. Susanita Chirusi representa la visión tradicional de la 
mujer. Su sueño es casarse y tener hijos, lo cual contrasta con el espíritu crítico de Mafalda. Libertad es mucho más liberal que Mafalda y desea la independencia total de la mujer. Felipe es un año mayor que Mafalda y está en un curso superior. Es tímido y generalmente tiene dificultades para hacer las tareas escolares. Miguelito es el más ingenuo de todos los amigos de Mafalda. Es hijo único y tiene una madre muy estricta. Guille es el hermano de Mafalda que usa chupete y habla en media lengua. Es inocente y hace travesuras.

6 Aunque estoy de acuerdo con Brittany Nicolle Tullis que el ángel del hogar es una figura importante en la construcción de la feminidad en los años sesenta del siglo pasado, hay que recordar que dicho prototipo surge en el sigloXVI, se afianza en el siglo XIX y persiste hasta bien entrado el siglo XX. Como sostienen Elisabeth Bronfen, Sandra Gilbert y Susan Gubar, en la representación de la mujer en la literatura del siglo XIX europea prevalecieron los modelos del ángel o hada del hogar y la mujer monstruo que aparecían en novelas clásicas como Jane Eyre de Charlotte Brontë. En el contexto latinoamericano, se aprecia el prototipo del ángel del hogar en novelas como María de Jorge Isaacs, modelo que se desvirtúa en Dolores y en Una holandesa en América de la colombiana Soledad Acosta de Samper.

7 Esta tendencia de Mafalda a cuestionar que Raquel no tenga una profesión fuera del hogar se hace patente en las cuarenta ocho tiras publicadas en Primera Plana, y en particular, en las publicadas entre el Io y al I7 de noviembre de 1964. En dichas tiras, Mafalda recrimina a Raquel no haber seguido con sus estudios cuando se casó. La crítica también va dirigida a su padre cuando lo acusa de “Oscurantista!” por impedir que Raquel consiguiera un título universitario (Lavado 542).

8 Para Roman Gubern y Luis Gasca, en los cómics se utilizan por lo menos dos tipos de espacios. El primero es el encuadre donde aparece la acción representada. El segundo corresponde al espacio narrativo que se crea a través de la figuración. En el encuadre se utiliza el espacio en on para indicar todo lo que ocurre dentro del marco de la tira y espacio en off para indicar lo que está fuera del encuadre.

\section{OBRAS CITADAS}

A $\operatorname{costa}$ DE SAMPER, SOLEDAD. "Aptitud de la mujer para ejercer todas las profesiones." Revista de Estudios Sociales 38 (2011): 169-75.

—. Dolores. Soledad Acosta de Samper: una nueva lectura. Ed. Montserrat Ordoñez. Bogotá : Fondo Cultural Cafetero, 1988. 26-86.

—. Una holandesa en América. Ed. Catharina Vallejo. Bogotá: Uniandes, 2006.

B ERGADo, R OBERTo. "El uso del color en los cómics." Cómics: Manual de

instrucciones. Eds. Roberto Bergado, et al. Bilbao: Astiberri, 2016. I29-40. 
B E Rg Son, henR I. La risa. Trad. Amalia Aydée Raggio. Madrid: Sarpe, 1985. S. pag. Web.

B R o n F n, E l ISA B th. Over Her Dead Body: Death, Femininity and the Aesthetic. New York: Routledge, I993.

Cantero rosales, Ángeles. “De 'Perfecta casada' a 'Ángel del hogar' o la construcción del arquetipo femenino en el siglo XIX." Tonos: Revista Electrónica de Estudios Filológicos I4 (2007): S. pag. Web.

Cast ellan os, rosario. “Lección de cocina.” Álbum de familia. México: Joaquín Mortiz, 1971. 7-22.

—. Mujer que sabe latín. México: Secretaría de Educación Pública, 1973.

collins, Rebecca L. "Content Analysis of Gender Roles in Media: Where Are We Now and Where Should We Go?" Sex Roles 64 (2011): 290-98.

cosse, is a b L L a. “Claudia: la revista de la mujer moderna en la Argentina de los años sesenta (I957-1973)" Mora I7.I (20II): S. pag. Web.

—. "Ese monstruito: Mafalda, generaciones y género en una construcción mítica." Revista latinoamericana de ciencias sociales, niñez y juventud I4.2 (2010): 1549$6 \mathrm{I}$.

—. Mafalda: historia social y política. Buenos Aires: Fondo de Cultura Económica, 2014 .

D UnCA n, NA NCy. BodySpace: Destabilizing Geographies of Gender and Sexuality. New York: Routledge, 1996.

e co, u m B e r t o. Prólogo. Mafalda, la contestataria. Por Joaquín Lavado (Quino). Milán: Bompiani, I969. I-I2.

E L T IT, Diamela. "Vueltas y revueltas." Debate feminista 35 (abril 2007): 15I-57. fernández l'hoeste, héctor. "From Mafalda to Boogie. The City and Argentine Humor." Imagination Beyond Nation: Latin American Popular Culture. Eds. Eva Paulino Bueno y Terry Caesar. Pittsburgh: U of Pittsburgh P, I998. 8I-IO6.

FERnÁndeZ L'h oeste, héctor y JUAn poblete, eds. Redrawing the Nation: National Identity in Latin/o American Comics. New York: Palgrave MacMillan, 2009 .

F o STE R, DA Vid Wil liam. From Mafalda to Los Supermachos: Latin American Graphic Humor as Popular Culture. Boulder: Lynne Rienner, I989.

GILBERT, SANDRA, y SUSAN GUBAR. The Madwoman in the Attic: The Woman

Writer and the Nineteenth-Century Imagination. New Haven and London: Yale UP, 2000.

GOCIOL, JUDith. "Textos e investigación periodística." Joaquín Lavado (Quino). 2I$65 \mathrm{I}$.

GONZÁLEZ hermosilla, ALEJANDRA LORETo. "El binomio identidad y cultura presentes en la historieta chilena Condorito. Aproximaciones conceptuales y 
análisis histórico social en la realidad nacional." Perspectivas de la comunicación 6.2 (2013): 52-64.

GUB ERn, ROMAN, y Luis Gasca. El lenguaje de los cómics. Barcelona: Península, I98I.

LAVAdo, JoA Quín ( Q Uino). Toda Mafalda. Buenos Aires: Ediciones de la Flor, 1993.

"Le tr e ro." Video em línea. Condorito Plop! World Editors, 20I9. Web. 4 octubre 2018.

MASO T TA, ó SCAR. La historieta en el mundo moderno. Buenos Aires: Paidós, 1970.

MASSE y, Dor E En. Space, Place and Gender. Cambridge: Polity P, 1994.

MONTEALEGRE, JORGE. "Identidad y representaciones en un mundo globalizado. El cóndor: familiaridad cultural e identidades diversas." Polis: Revista Latinoamericana i8 (2008): S. pag. Web.

MONTES GARCÉS, ELIZABETH. "La desintegración corporal vs. la construcción textual en Dolores de Soledad Acosta de Samper." Letras Femeninas 30.I (2004): $120-28$.

m or Re Ll, Jo h n. Comic Relief: A Comprehensive Philosophy of Humor. West Essex: Wiley-Blackwell, 2009.

p o B Lete, ju An. "Condorito: Chilean Popular Culture and the Work of Meditation." Fernández L'Hoeste y Poblete. 35-53.

RESNiCK, CLAUdia, y PAULA K. SPECK. “'Quino' After Mafalda: A Bittersweet Look at Argentine Reality." Studies in Latin American Popular Culture 2 (1983): 79-87.

ríos boettiger, René (PePo). Condorito. Portada. 8 septiembre 2006. Santiago de Chile: Editorial Televisa Chile.

—. "Decente." (42.056) Condorito. Historieta. Santiago de Chile: Editorial Televisa. 9 septiembre $200 \mathrm{I}$.

—. "Inflable." (52.045) Condorito. Historieta. 24 julio 2007. Santiago de Chile: Editorial Televisa Chile.

—. "Puesto." (45.615) Condorito. Historieta. 8 septiembre 2006. Santiago de Chile: Editorial Televisa Chile.

—. "Vuelta." (45.837) Condorito. Historieta. 25 julio 2003. Santiago de Chile: Editorial Televisa Chile.

"Las siete vidas de un símbolo nacional." Memoria chilena. Biblioteca Nacional de Chile. 27 mayo 20I7. S. pag. Web.

T U L IS, B R IT TAN Y N C O LE. Constructions of Femininity in Latin/o American Comcis: Redefining Womanhood Via the Male-Authored Comic. 2014. Tesis. University of Iowa.

VILLAGRA, NiCOLE. "Condorito no siempre fue igual: Conoce la evolución de Condorito desde 1949 hasta la actualidad." Bibliochile.cl. 15 diciembre 2012 . S. pag. Web.

W I L L E, MA R K. "Untitled: The Housing of Gender." Sexuality and Space. Ed. Beatriz Colomina, New York: Princeton Architectural P, I992. 332-5I. 
ANEXOS
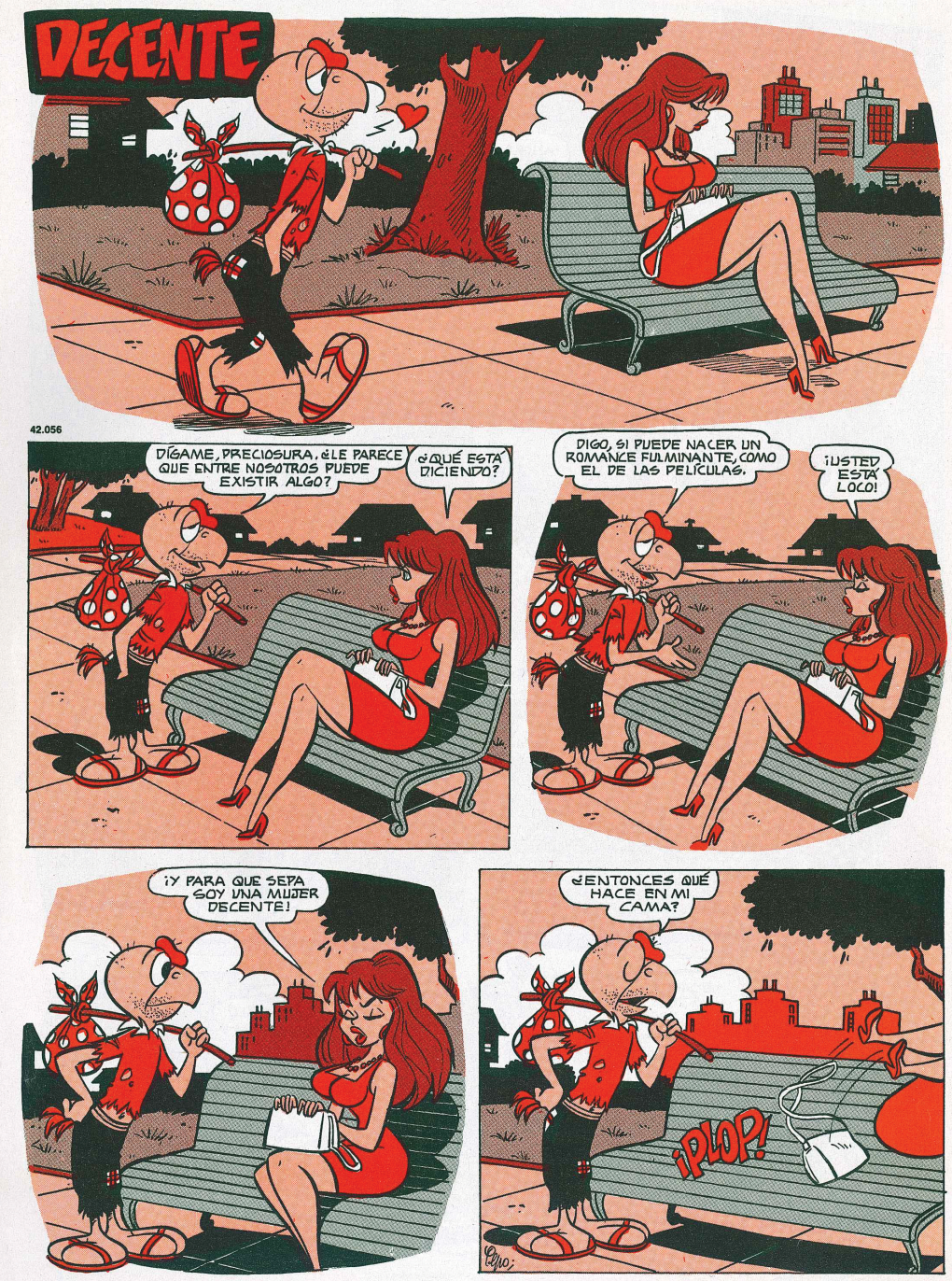

Figura I 


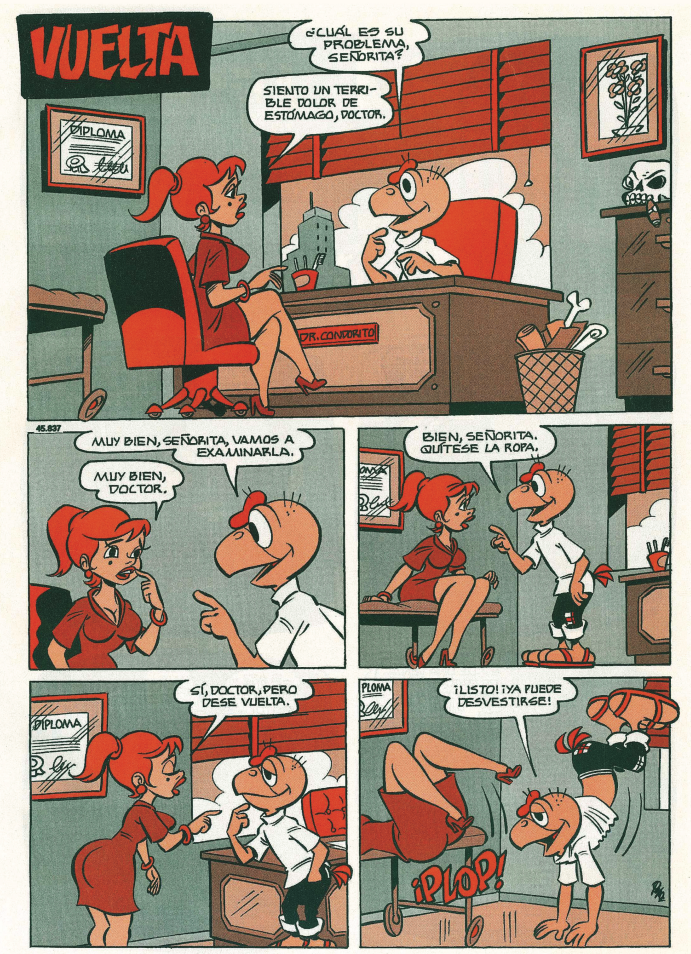

Figura 2

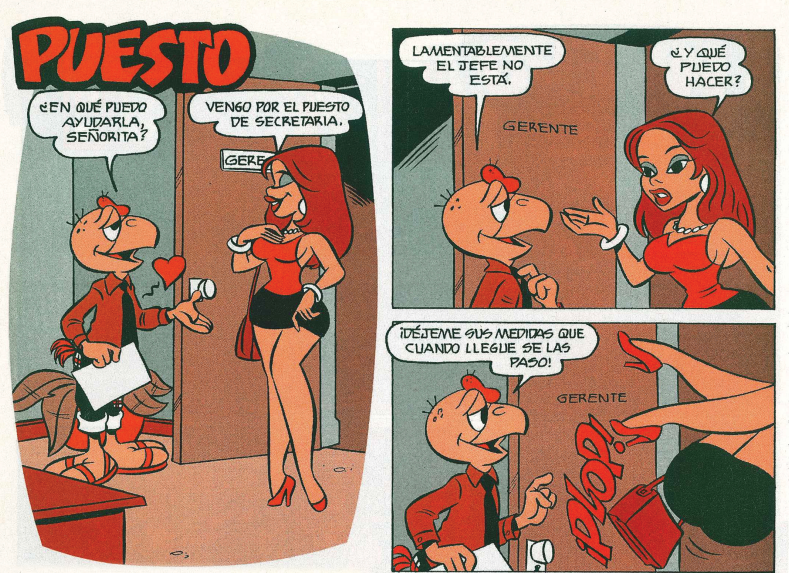

Figura 3 


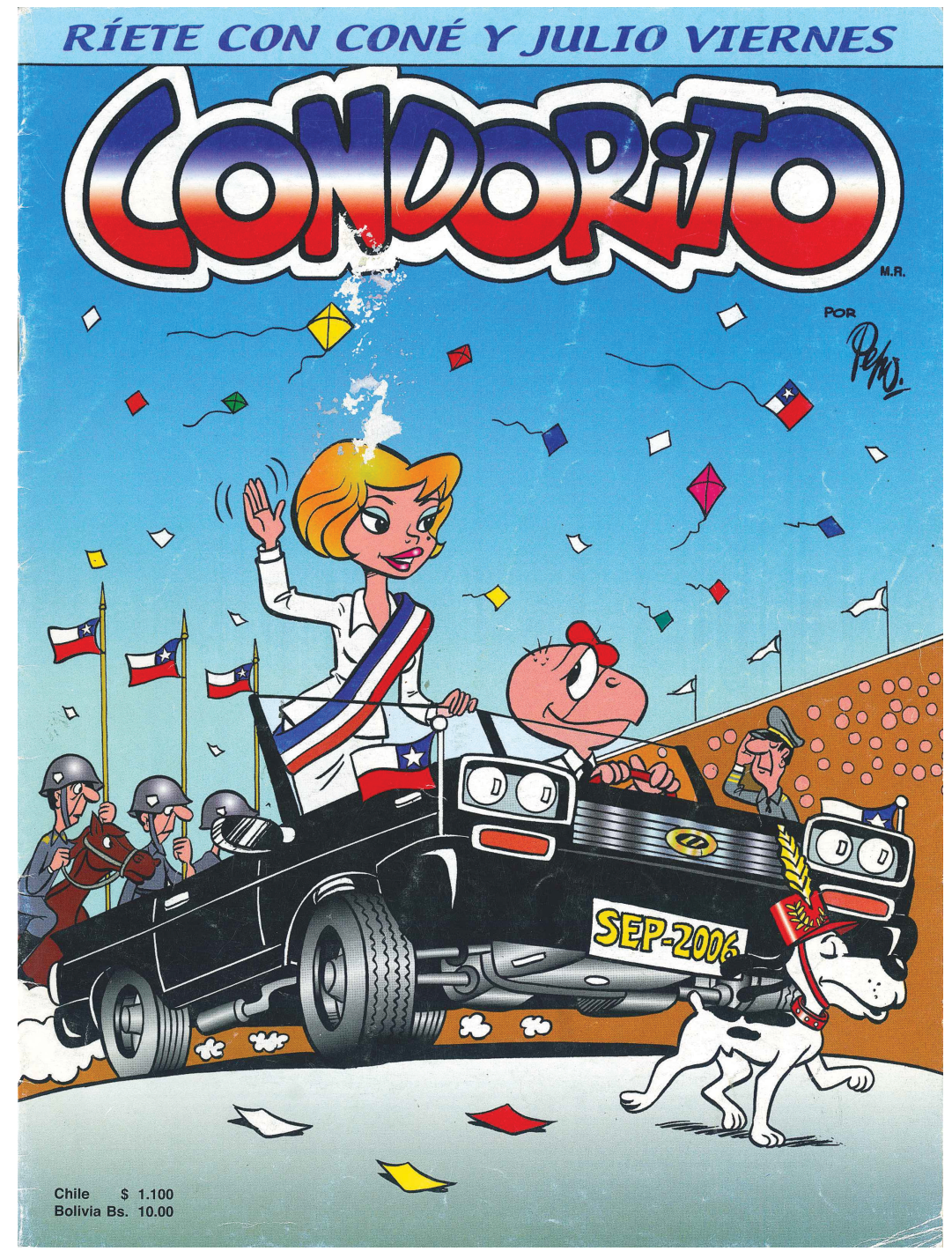

Figura 4 


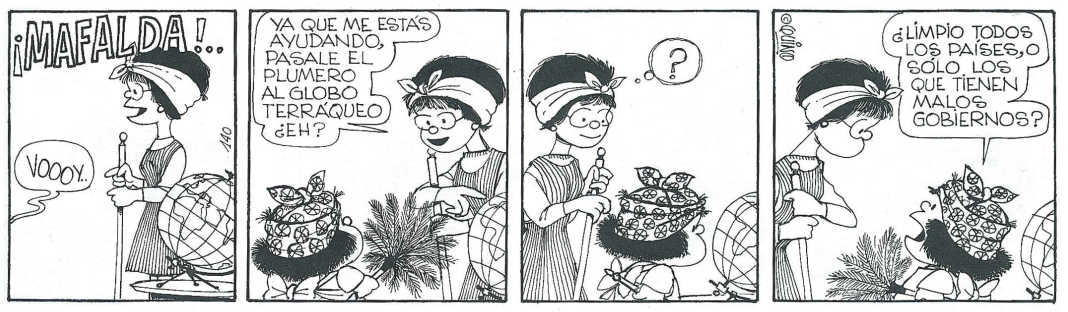

Figura 5

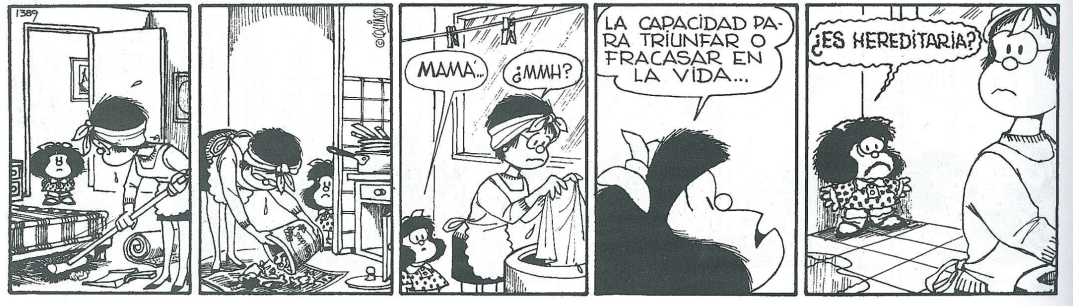

Figura 6
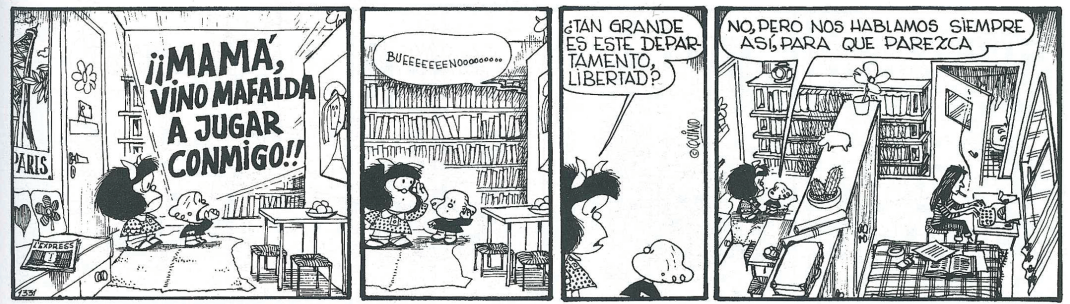

Figura 7
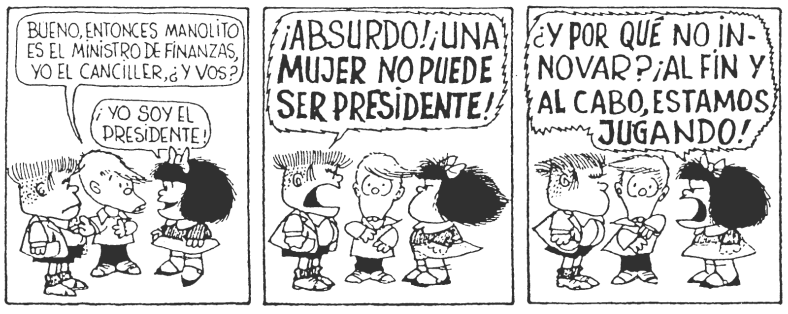

PORQUE NI JUGANDO,

A NADIE QUE QUIERA

INNOVAR SE LO DE-

(JA SER PRESIDENTE

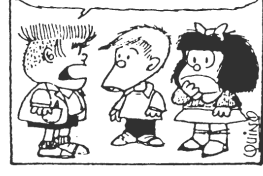

Figura 8 